\title{
Spatial reliability analysis of a concrete bridge subject to corrosion conditional on monitoring results
}

\author{
Johannes Fischer \& Daniel Straub \\ Engineering Risk Analysis Group, Technische Universität München, Germany
}

\begin{abstract}
For reinforced concrete bridges, corrosion monitoring is increasingly considered for assessing the state of the structure. Data from corrosion sensors can be used to update the estimate of the corrosion probability and, ultimately, to update the reliability of the structure. In this paper, a Bayesian updating procedure is proposed and implemented for this purpose. The procedure accounts for the spatial correlation of the corrosion process in the structure and enables one to compute the reliability of a bridge conditional on the corrosion monitoring data. The bridge reliability model is based on a simplified probabilistic model calibrated to code requirements. The procedure is demonstrated by an application to a highway bridge. Special focus is given to investigating the influence of the spatial correlation of corrosion on the reliability updating.
\end{abstract}

\section{INTRODUCTION}

Corrosion is a widespread phenomenon in engineering structures. As an example, chloride-induced corrosion triggers about $66 \%$ of all concrete-bridge damages in Germany (Schieß1 \& Mayer, 2007), leading to large costs for maintenance and repair.

Corrosion sensors are increasingly installed on bridge decks for improved planning of repair or replacement actions (Holst et al., 2011; Holst \& Budelmann, 2012). To make better use of the information obtained from such monitoring, it should be incorporated into a quantitative model of the structural integrity. This can be achieved effectively through a Bayesian updating of the corrosion model.

This article introduces a method for Bayesian updating of the reliability of concrete bridges that are subject to chloride-induced reinforcement corrosion, using results from corrosion sensors. The method uses a state-of-the-art deterioration model to characterize the process of chloride ingress and corrosion initiation (Gehlen, 2000; Malioka, 2009). To model the corrosion process, a simple linear deterioration model is applied.

Since the corrosion processes at different locations in a structure are correlated, measurement results at a location also contain information on nearby locations. To address this effect, the parameters of the corrosion model are represented by spatial random fields. Based on the spatial model, it is shown how monitoring results can be used to update the probability of corrosion at all locations in the structure.
Furthermore, the effect of the corrosion monitoring on the overall bridge reliability is quantified. To this end, the Bayesian update of the corrosion probability is combined with a simple bridge reliability model, which is obtained by a calibration to code requirements.

The proposed procedure is demonstrated by an application to a highway bridge. Special focus is given to investigating the effect of assumptions on the spatial correlation of corrosion on the updated corrosion probability and on the updated bridge reliability.

\section{DETERIORATION MODELING}

Chloride-induced corrosion can be subdivided into two phases: (a) the diffusion process of chloride ions into the concrete leading to corrosion initiation and (b) the corrosion of the reinforcement leading to a loss of steel cross section and bond.

For corrosion initiation (a), a well-developed deterioration model is available and applied in this study. For the propagation process (b), a simplified model is utilized, which describes the loss of cross section area of the reinforcement steel as a linear function of time.

\subsection{Modeling of the corrosion initiation process}

The ingress of chloride ions into the concrete surface is commonly described by Fick's $2^{\text {nd }}$ diffusion law (Gehlen, 2000). The chloride concentration $C(z, t)$ at time $t$ in depth $z$ is given by 
$C(z, t)=C_{\mathrm{S}} \cdot\left(1-\operatorname{erf}\left(\frac{z}{\sqrt{4 D t}}\right)\right)$,

in which $D$ denotes the uncertain diffusion coefficient and $C_{\mathrm{S}}$ denotes the random surface chloride concentration. $\operatorname{erf}(\cdot)$ is the Gauss error function.

In contrast to the model assumption in Eq. (1), the diffusion constant $D$ is not constant in time and depends on concrete properties as well as environmental influences. Appropriate models have been developed to describe the dependency of the diffusion coefficient $D$ on time, concrete properties, and curing time. Therein, the diffusion coefficient $D(t)$ is defined as:

$D(t)=D_{0} \exp \left(B_{\mathrm{e}} \cdot\left(\frac{1}{T_{\text {ref }}}-\frac{1}{T_{\text {real }}}\right)\right) \cdot K_{\mathrm{t}} \cdot\left(\frac{t_{o}}{t}\right)^{A}$,

where $D_{0}, B_{\mathrm{e}}, K_{\mathrm{t}}, T_{\text {ref }}, T_{\text {real }}, t_{0}$, and $A$ are factors to describe the dependency of the diffusion coefficient on environmental influences and concrete properties, and to adapt the in-labor conditions to the real environment. Here, it is $K_{\mathrm{t}}=1$. The uncertain parameters of the diffusion model are summarized in the vector $\mathbf{X}=\left[C_{\text {crit }}, C_{\mathrm{S}}, D_{0}, A, W, B_{\mathrm{e}}, T_{\text {real }}\right]^{\mathrm{T}}$. Probabilistic models for these parameters can be found in DuraCrete (1999).

Corrosion occurs when the chloride concentration at the reinforcement reaches a critical level $C_{\text {crit }}$. For a reinforcement in depth $z$, the time to corrosion initation can now be computed by combining Eqs. (1) and (2) and solving for $t$, resulting in

$T_{\text {init }}\left(\mathbf{X}, z_{i}\right)$

$=\left(D_{0} K_{e} t_{0}^{A}\right)^{\frac{1}{A-1}} \times\left(\frac{z_{i}}{2 \operatorname{erf}^{-1}\left(1-\frac{C_{\text {crit }}}{C_{S}}\right)}\right)^{\frac{2}{1-A}}$,

where

$K_{e}=\exp \left(B_{\mathrm{e}} \cdot\left(\frac{1}{T_{\text {ref }}}-\frac{1}{T_{\text {real }}}\right)\right)$.

\subsection{Spatial modeling of the corrosion initiation}

The corrosion processes at different locations in a structure are correlated, due to common environmental influences and spatial dependences of concrete properties. To represent this correlation, the uncertain model parameters $\mathbf{X}$ are modeled through spatial random fields. Random-field modeling of reinforcement corrosion in RC structures has been considered in several studies (Hergenröder, 1992; Stewart \& Mullard, 2007; Malioka, 2009). However, up to now only limited information on the spatial correlation among the corrosion parameters is available.
To model the spatial distribution of corrosion, the concrete surface is discretized in elements of size $0.5 \mathrm{~m} \times 0.5 \mathrm{~m}$, as depicted in Figure 1 .

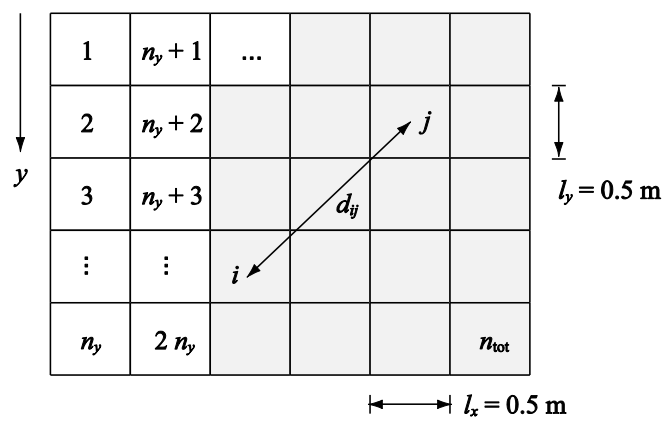

Figure 1: Spatially discretized concrete surface.

In this study, the spatial covariance of each spatially distributed parameter $X_{k} \in \mathbf{X}$ is modeled through a monotonically decreasing correlation function

$\rho_{i j}=(1-c) \cdot \exp \left(-\frac{d_{i j}}{l_{X}}\right)+c$,

where $d_{i j}$ is the distance between two locations $i$ and $j$ on the concrete surface (Figure 1), $l_{X}$ is the correlation length, and $c$ is a constant describing the dependency for infinitely distant locations. The covariance function is defined as $\operatorname{Cov}\left[X_{k a}, X_{k b}\right]=\sigma_{X_{k}}^{2} \rho_{i j}$, where $\sigma_{X_{k}}$ is the standard deviation of the model random variable $X_{k}$. Figure 2 illustrates the correlation function $\rho_{i j}$ for three investigated correlation models.

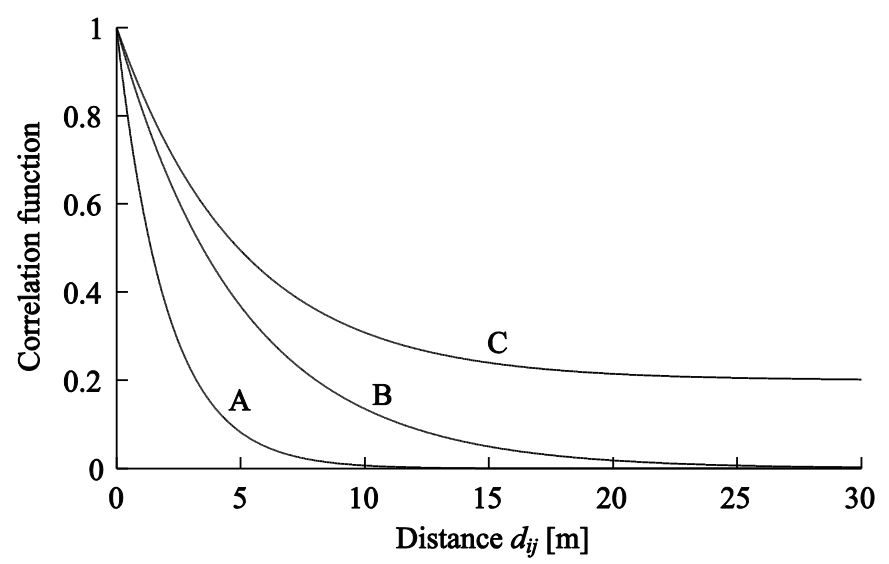

Figure 2: The correlation function in Eq. (5) for different parameter values (A: $c=0, l=2 \mathrm{~m}$; B: $c=0, l=5 \mathrm{~m}$; C: $c=0.2$, $l=5 \mathrm{~m})$.

\subsection{Modeling of the corrosion propagation}

The corrosion propagation phase is here described through a simplified linear model. The remaining area of steel cross section $A(t)$ is written as 


\section{$A(t)$}

$= \begin{cases}A_{0}, & t<T_{\text {init }} \\ A_{0}\left(1+\frac{T_{\text {init }}}{T_{\mathrm{P}}}\right)-\frac{A_{0}}{T_{\mathrm{P}}} \cdot t, & T_{\text {init }} \leq t \leq T_{\text {init }}+T_{\mathrm{P}} \\ 0, & t>T_{\text {init }}+T_{\mathrm{P}}\end{cases}$

where $A_{0}$ is the original cross section area, $T_{\text {init }}$ is the time to corrosion initiation, (see Eq. (3)), and $T_{\mathrm{P}}$ is the propagation time. The model is illustrated in Figure 3.

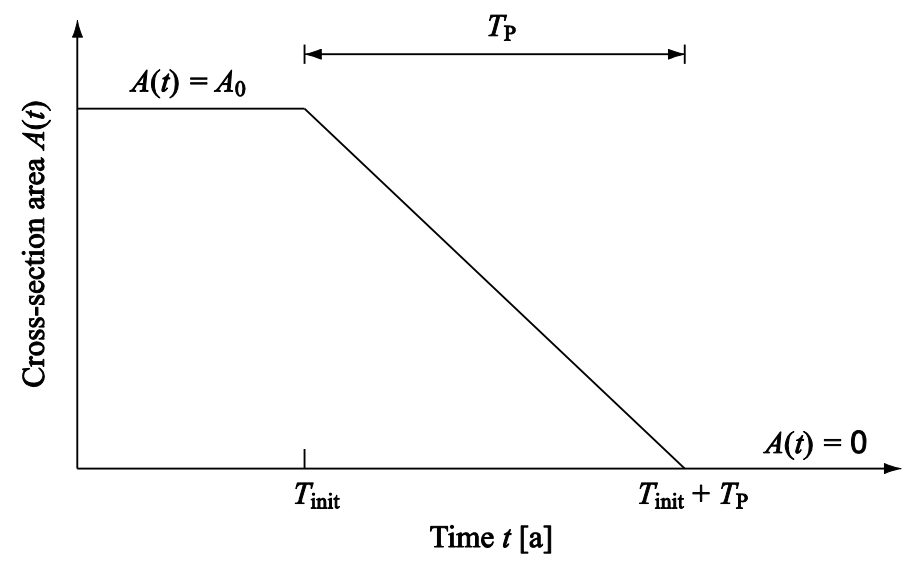

Figure 3: The corrosion propagation model.

\section{RELIABILITY ESTIMATION}

To compute the reliability of the bridge conditional on the remaining cross section area $A(t)$, a simple model is proposed in the following, which is based on the relevant code requirements.

The load on the bridge is characterized by $M_{S}$, the annual maximum bending moment in the middle of the bridge span. $M_{S}$ is assumed to be described by the Gumbel distribution with cumulative distribution function (CDF)

$F_{M_{S}}\left(m_{S}\right)=\exp \left(-\exp \left(-\frac{m_{S}-\xi}{\eta}\right)\right)$,

whose distribution parameters $\eta$ and $\xi$ are obtained through calibration: The European standard DIN EN 1990 (2010) requires a reliability index $\beta \geq 4.7$ for one year of exposition. On this basis, it is assumed that the bridge in its initial state (i.e. with cross section area $A_{0}$ ) has reliability $\beta=4.7$. Since the capacity of the bridge in its initial state, $m_{R 0}$, can be computed, one obtains the following condition:

$$
1-F_{M_{S}}\left(m_{R 0}\right)=\operatorname{Pr}\left(M_{S} \geq m_{R 0}\right)=\Phi(-4.7) \text {. }
$$

Assuming a coefficient of variation (c.o.v.) of 0.3 for $M_{S}$, the parameters $\eta$ and $\xi$ can be determined with the condition of Eq. (8). The probability of bridge failure with reduced reinforcement cross section area $A(t)$ can now be estimated as

$\operatorname{Pr}(F \mid A(t)=a)=\operatorname{Pr}\left(M_{S} \geq m_{R}(a)\right)$, where $m_{R}(a)$ is the bending capacity in mid-span with reinforcement cross section area $a$. Applying the rule of total probability, the failure probability of the bridge in year $t$ can be calculated as

$\operatorname{Pr}(F)=\int_{0}^{A_{0}} \operatorname{Pr}(F \mid A(t)=a) f_{A(t)}(a) \mathrm{d} a$,

where $f_{A(t)}(a)$ is the probability density function (PDF) of the steel cross section $A(t)$, computed through Eq. (6).

\section{RELIABILITY UPDATING AND MODELING OF CORROSION SENSORS}

\subsection{Reliability updating}

Inspections or monitoring of the structure, where model parameters or the model output itself are measured, provide information on the deterioration process. This information can be used to update the corrosion probability and the reliability of the bridge. The inspection or monitoring outcome can be represented by an event $Z$, described by a limit-state function $h(\mathbf{x})$ (Straub, 2011).

Corrosion sensors provide information on the event of corrosion initiation at the sensor locations (see Figure 4), and, indirectly, on corrosion initiation elsewhere in the structure. Let $E_{i}(t)$ be the event of corrosion initation at location $i$ at time $t$. To assess the effect of the monitoring outcome, the conditional probability of $E_{i}(t)$ given $Z$ is computed as

$$
\begin{aligned}
\operatorname{Pr}\left(E_{\text {init }} \mid Z\right) & =\frac{\operatorname{Pr}\left(E_{i}(t) \cap Z\right)}{\operatorname{Pr}(Z)} \\
& =\frac{\int_{\mathbf{X}} \operatorname{Pr}\left(E_{i}(t) \mid \mathbf{x}\right) \operatorname{Pr}(Z \mid \mathbf{x}) f(\mathbf{x}) \mathrm{d} \mathbf{x}}{\int_{\mathbf{X}} \operatorname{Pr}(Z \mid \mathbf{x}) f(\mathbf{x}) \mathrm{d} \mathbf{x}}
\end{aligned}
$$

where $\operatorname{Pr}(Z \mid \mathbf{x})=L(\mathbf{x} \mid Z)$ is the likelihood function. It quantifies the probability of a measurement or monitoring result for given values of $\mathbf{x}$. The likelihood is central to the updating procedure and it will be developed for the corrosion-sensor monitoring in the following section.

The procedure introduced in Eq. (11) is commonly referred to as Bayesian updating or information updating, and has been applied in the context of structural reliability since the 1970s (Tang, 1973; Madsen, 1987; Straub, 2011). Here the computational method for Bayesian updating developed in Straub (2011) is utilized. The implementation of the method to spatial updating of the corrosion probability is given in Fischer \& Straub (2013).

\subsection{Probabilistic modeling of corrosion sensors}

One option for monitoring of reinforcement corrosion in concrete structures is to install corrosion sensors, 
which are mounted to the reinforcement. These corrosion sensors provide time-continuous information on the chloride concentration at two levels $z_{i}$ below the concrete surface (Figure 4).

The corrosion sensors consist of two steel wires installed at depths $z_{i}$ from the concrete surface. These wires are connected to an electrical device that measures the wire's electrical resistance. This resistance changes when the wire corrodes. Since the wires are made of the same material as the reinforcement, it is assumed that they start to corrode at the same chloride concentration $C_{\text {crit }}$ as the reinforcement. When the measured electrical resistance indicates corrosion, a signal is triggered. The corrosion signal should first occur at the wire that is closer to the concrete surface because the chloride concentration decreases with increasing distance from the concrete cover (Figure 4).

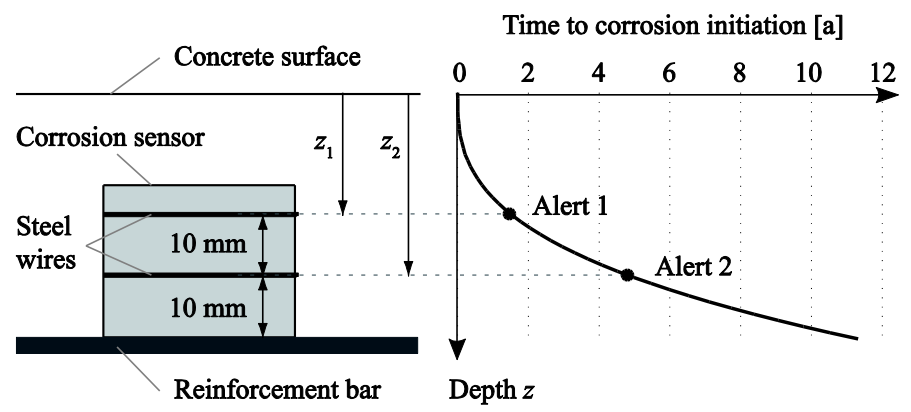

Figure 4: The corrosion sensor and the point in time of corrosion initiation at depths $z_{1}$ and $z_{2}$ of the corrosion-sensor wires.

Measurement devices are subject to measurement errors, generally induced by imprecise testing methods and human malfunction (Thöns, 2011). Here, measurement errors are due to dissimilarities in the wire and reinforcement steel, inexact voltage measurement, or imprecise vertical positioning of the sensors on the reinforcement. This is accounted for by considering a normally distributed measurement error $\epsilon_{\mathrm{m}}$ on the time of corrosion initiation at the sensor wires.

The time of corrosion initiation at the sensor-wire positions is found by solving Eq. (1) for $T$ inserting the levels $z_{i}$ of the corrosion-sensor wires instead of $z$; the solution is presented in Eq. (3).

Be $T_{\text {init }}\left(\mathbf{X}, z_{k i}\right)$ the predicted point in time of corrosion initiation at depth $z_{i}$ at location $k$ on the concrete surface and $T_{\mathrm{m}, \mathrm{k} i}$ the time when the alarm is released at that location. The relationship between $T_{\mathrm{m}, \mathrm{k} i}$ and $T_{\text {init }}\left(\mathbf{X}, z_{k i}\right)$ is

$T_{\text {init }}\left(\mathbf{X}, z_{k i}\right)=T_{\mathrm{m}, \mathrm{k} i}-\epsilon_{\mathrm{m}}$.

It follows that $\epsilon_{\mathrm{m}}=T_{\mathrm{m}, \mathrm{k} i}-T_{\text {init }}\left(\mathbf{X}, z_{k i}\right)$ and the Likelihood function at location $k$ at depth $z_{i}$ is given by

$L_{k i}\left(\mathbf{x} \mid T_{\mathrm{m}, k i}\right)=f_{\epsilon_{\mathrm{m}}}\left(T_{\mathrm{m}, k i}-T_{\text {init }}\left(\mathbf{X}, z_{k i}\right)\right)$.
It is assumed that measurement errors $\epsilon_{\mathrm{m}}$ of the sensor alerts are statistically independent of each other and of the basic random variables $\mathbf{X}$. Therefore, the likelihood for one sensor $k, L_{k}\left(\mathbf{x} \mid \cap_{i} T_{\mathrm{m}, k i}\right)$, is obtained by multiplying the likelihood functions in Eq. (13) over the two depths of the sensor wires $z_{i}$.

If several corrosion sensors are installed, the total Likelihood function is given by the product of the Likelihood functions of all wires in all sensors as

$$
\begin{aligned}
& L\left(\mathbf{x} \mid \bigcap_{\mathrm{all}} T_{k, i} T_{\mathrm{m}, k i}\right) \\
&=\prod_{\text {all }} \prod_{k} \prod_{\text {all } i} f_{\epsilon_{\mathrm{m}}}\left(T_{\mathrm{m}, \mathrm{k} i}-T_{\text {init }}\left(\mathbf{X}, z_{k i}\right)\right) .
\end{aligned}
$$

The Bayesian update of the corrosion probability conditional on the sensor alerts is performed jointly for all elements of the discretized concrete surface, For detailed description of the updating procedure, we refer to Straub (2011) and Fischer \& Straub (2013).

\section{APPLICATION EXAMPLE}

The method is applied to a representative German highway bridge that was built in 1967 from prestressed concrete. The bridge was constructed as a pre-stressed box girder, continuously spanned over two fields with a total length of $65.3 \mathrm{~m}$ and a width of $18.5 \mathrm{~m}$. The bridge is subject to high traffic loads and concentrated chloride attacks due to the disposal of deicing salt, which is one of the harshest triggers of the chloride corrosion. The case study is hypothetical insofar as no corrosion sensors were installed on this bridge, and the effect of the assumed monitoring outcomes on the reliability of the bridge is thus computed for illustration purposes only. For the calculations reported in this paper, the bottom plate over one field of the bridge is considered. The dimensions of the plate are $5 \mathrm{~m} \times 30 \mathrm{~m}$.

\subsection{Modeling of corrosion initiation and propagation}

The prior estimate of the corrosion probability is found using the model parameters introduced in Sec. 2 and quantified in Table 1 (DuraCrete, 1999). The results are shown in Figure 5. The prior calculation indicates a corrosion probability of $64 \%$ after 45 years in service. 


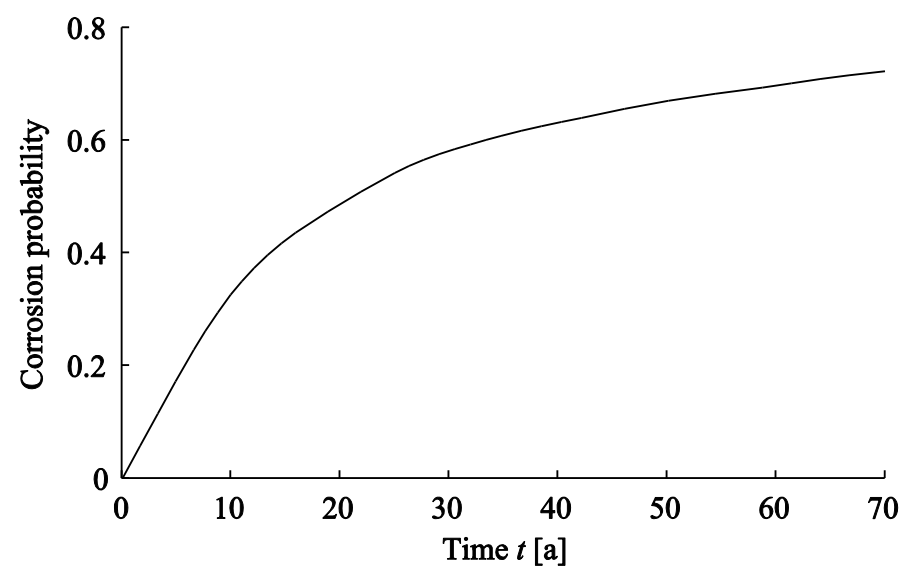

Figure 5: The prior corrosion probability using the model parameters in Table 1.

Table 1: Model parameters for the corrosion models introduced in Sec. 2 (e.g. DuraCrete, 1999; Malioka, 2009).

\begin{tabular}{llll}
\hline RVs X & Dimension & Distribution & Mean and standard dev. \\
\hline$C_{\mathrm{S}}$ & {$[\mathrm{M} .-\%]^{*}$} & LogNormal & $\mu=2,7 ; \sigma=1,23$ \\
$C_{\text {crit }}$ & {$[\mathrm{M} .-\%]^{*}$} & Beta $(\in[0 ; 2])$ & $\mu=0,6 ; \sigma=0,15$ \\
$W$ & {$[\mathrm{~mm}]$} & LogNormal & $\mu=40 ; \sigma=12$ \\
$D_{0}$ & {$\left[10^{-12} \mathrm{~m}^{2} / \mathrm{s}\right]$} & Normal & $\mu=498,3 ; \sigma=99,7$ \\
$A$ & {$[-]$} & Beta $(\in[0 ; 1])$ & $\mu=0,3 ; \sigma=0,12$ \\
$T_{\text {Ref }}$ & {$[\mathrm{K}]$} & Deterministic & $T_{\text {Ref }}=293$ \\
$T_{\text {Real }}$ & {$[\mathrm{K}]$} & Normal & $\mu=282 ; \sigma=3$ \\
$B_{\mathrm{e}}$ & {$[\mathrm{K}]$} & Normal & $\mu=4800 ; \sigma=700$ \\
$T_{P}$ & {$[\mathrm{a}]$} & LogNormal & $\mu=20 ; \sigma=6$ \\
\hline
\end{tabular}

* The dimension [M.-\%] is mass-percent of cement.

The spatial correlation of the parameters $C_{\mathrm{S}}, W$, $D_{0}, C_{\text {crit }}$, and $T_{\mathrm{P}}$ is modeled with the correlation model of Eq. (5); the parameter $A$ is assumed to be fully correlated. Unless otherwise stated, correlation model B of Figure 2 is used in the case study.

\subsection{Modeling of the corrosion-sensor monitoring}

Three corrosion sensors are assumed to be installed at the locations shown in Figure 6.

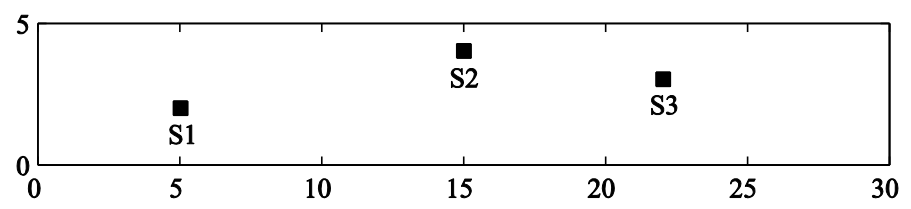

Figure 6: Locations S1, S2, and S3 of the corrosion sensors on the concrete surface.

The sensor measurement results are provided in Table 2.

Table 2: Positions and alert times of the corrosion sensors.

\begin{tabular}{l|l}
\hline Position $\left(x_{k}, y_{k}\right)[\mathrm{m}]$ & Time of alert, $t_{k}\left(z_{i}\right)[\mathrm{a}]$ \\
\hline S1: $(5,2)$ & {$[3,10]$} \\
S2: $(15,4)$ & {$[1.2,3.7]$} \\
S3: $(22,3)$ & {$[0.5,3]$} \\
\hline
\end{tabular}

A normally distributed error $\epsilon_{\mathrm{m}}$ of the sensor measurement is assumed, with zero mean and $\sigma_{\epsilon_{\mathrm{m}}}=2$ years.

\subsection{Corrosion probability conditional on the sensor alerts}

The corrosion probability conditional on the sensor signals is calculated combining Eqs. (14) and (11); its spatial distribution of the corrosion probability in year 45 is shown in Figure 7.

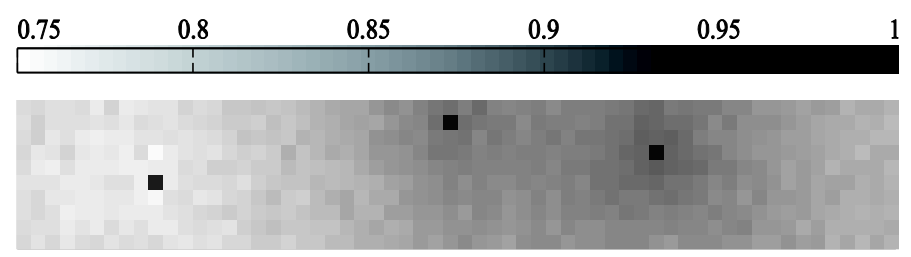

Figure 7: Corrosion probability over the concrete surface after 45 years in service, conditional on the corrosion-sensor monitoring results. The probability is in the range between $75 \%$ and $99 \%$.

The corrosion probability in year 45 conditional on the sensor alerts varies from $75 \%$ to $99 \%$; with a spatial mean of $82 \%$, the corrosion probability is higher than the prior estimate of $64 \%$. The locations of the corrosion sensors and their influence on the spatial update are clearly visible in Figure 7.

The first alert signal would be expected after about one year according to a first-order approximation of the initiation time following Eq. (3). Since the first alert was already triggered after 0.5 years, the posterior corrosion probability is higher than the prior estimate.

\subsection{Corrosion probability at different points in time}

To assess the effect of the corrosion sensor measurements at different points in time, the corrosion probability is evaluated for $t=\{15,45,70\}$ years, conditional on the sensor alerts, respectively (Figure 8).

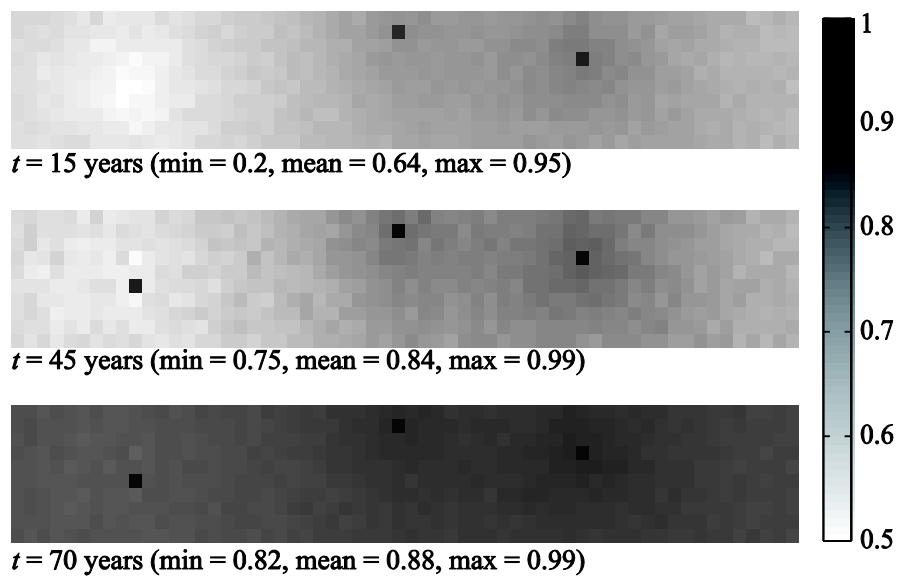

Figure 8: Estimated corrosion probability for the points in time $t=\{15,45,70\}$ years, conditional on the sensor signals. 
A comparison of the unconditional and conditional mean corrosion probability as a function of time is given in Figure 9. As expected, the mean of corrosion probability over the whole surface increases with time. Due to the early triggered sensor alerts, the mean of the corrosion probability conditional on the sensor signals is higher than the unconditional one.

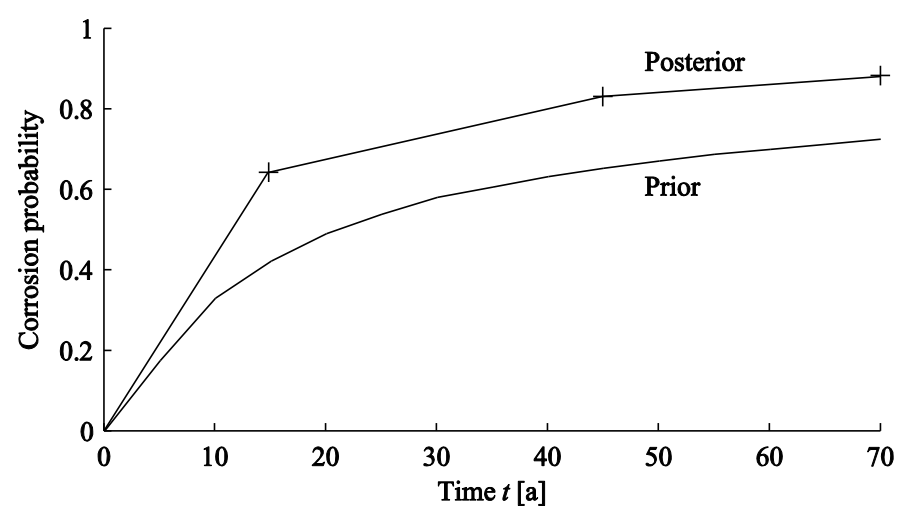

Figure 9: Comparison of the prior corrosion probability and the spatial mean of the corrosion probability conditional on the sensor alerts over the whole concrete surface.

\subsection{Bridge reliability}

The resistance of the bridge is computed deterministically as a function of the available reinforcement cross section $A(t)$. The pre-stressing steel has a characteristic yielding stress of $1250 \mathrm{~N} / \mathrm{mm}^{2}$ and fracture strength of $1400 \mathrm{~N} / \mathrm{mm}^{2}$, and has a cross-section area of $1.4 \times 10^{3} \mathrm{~mm}^{2}$. The available reinforcement cross section is determined as $A_{0}=52.1 \mathrm{~cm}^{2}$. The resulting initial bending-moment resistance is $m_{R}=$ 6.344 MNm. The annual maximum bending moment due to traffic loads is given by the Gumbel model introduced in Sec. 3 with parameters $\eta=3.68 \mathrm{MNm}$ and $\xi=1.36 \mathrm{MNm}$.

Figure 10 shows the failure probability of the bridge for a given amount of available reinforcement cross section $A(t)$ and corresponding bending resistance. The bending resistance at $A(t)=0$ is the one provided by the pre-stressing steel, which is here assumed to not deteriorate.

In the mid-span cross section of the bridge, the bottom plate is discretized into 10 elements. The reinforcement is assumed to be equally distributed to these elements, i.e. the initial steel cross section in each element is $5.2 \mathrm{~cm}^{2}$.

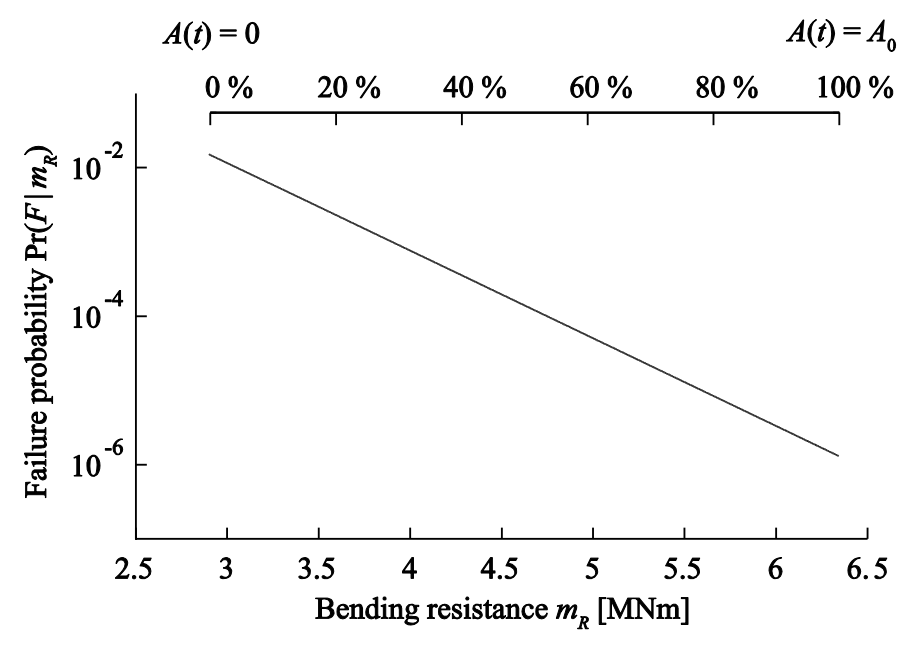

Figure 10: Failure probability $\operatorname{Pr}\left(F \mid m_{R}\right)$ conditional on available bending resistance on logarithmic scale.

Figure 11 shows the failure probability of the bridge as a function of time. Since the sensor alerts were triggered early, the failure probability conditional on the measurement results are higher than the ones based on the prior corrosion probability. Note that the corrosion probability in mid-span is influenced mostly by sensor S2.

Figure 11 also demonstrates the effect of the correlation model. In the unconditional case, the observed differences are due to the fact that the system is a redundant system. Increased statistical dependence among deterioration reduces the effective redundancy and, therefore, leads to higher probability of failure (correlation model $\mathrm{C}$ ).

Interestingly, the effect of the correlation model is similar for the results conditional on monitoring outcomes. This indicates that the influence of the correlation model on the spatial effect of the monitoring is limited. However, further investigations are required before a final conclusion can be drawn.

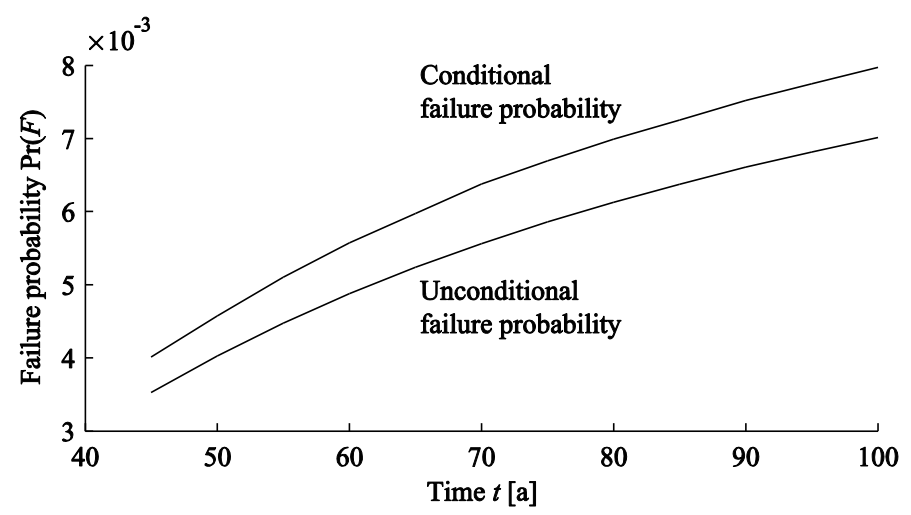

Figure 11: Failure probability of the bridge unconditional and conditional on the sensor-monitoring results.

\section{CONCLUSIONS}

This article presented a Bayesian updating procedure for updating the probabilistic corrosion model and the reliability estimate of a bridge with corrosion sensor monitoring results. The procedure accounts for the 
spatial correlation of the corrosion process in the structure. The procedure was demonstrated by an application to a highway bridge. Thereby, the effect of the spatial correlation model was investigated and found to have limited influence, even though the spatial influence is visible.

\section{ACKNOWLEDGMENT}

This work was performed as part of project FE 15.0508/2011/KRB (Fischer et al., 2013), funded by the German federal agency for streets and bridges (BASt).

\section{REFERENCES}

DIN EN 1990 (2010-12). Eurocode 0: Basis of structural design. CEN - European Committee for Standardization.

DuraCrete (1999). Models for Environmental Actions on Concrete Structures. DuraCrete: Probabilistic Performance Based Durability Design of Concrete Structures. The European Union - Brite EuRam III (Project BE95-1347/R3).

Fischer, J.; Schneider, R.; Thöns, S.; Rücker, W. \& Straub, D. (2013). Intelligente Bauwerke - Zuverlässigkeitsbasierte Bewertung von Brückenbauwerken unter Berücksichtigung von Inspektions- und Überwachungsergebnissen. Berichte der Bundesanstalt für Straßenwesen, Brücken- und Ingenieurbau (In print). In German.

Fischer, J. \& Straub, D. (2013). Bayesian updating of deterioration models with multiple spatially distributed inspections: Methodology and application to reinforcement corrosion in concrete structures. Manuscript to be submitted to Structural Safety.

Gehlen, C. (2000). Probabilistische Lebensdauerbemessung von Stahlbetonbauwerken. Zuverlässigkeitsbetrachtungen zur wirksamen Vermeidung von Bewehrungskorrosion. Deutscher Ausschuss für Stahlbeton (510). In German.

Hergenröder, M. (1992). Zur statistischen Instandhaltungsplanung für bestehende Betonbauwerke bei Karbonatisierung des Betons und möglicher Korrosion der Bewehrung. (PhD Thesis).

Holst, A. \& Budelmann, H. (2012). Low-cost sensor for integrated durability monitoring and life-cycle assessment of reinforced concrete structures. Proc. $3^{\text {rd }}$ International Symposium on Life-Cycle Civil Engineering, IALCCE 2012, Vienna, Austria, October 3-6 2012.

Holst, A.; Budelmann, H. \& Wichmann, H.J. (2011). Improved sensor concepts for durability monitoring of reinforced concrete structures. Proc. $8^{\text {th }}$ Intern. Workshop on Structural Health Monitoring (IWSHM 2011), Stanford, USA.

Madsen, H.O. (1987). Model updating in reliability theory. Paper presented at the Proc. $5^{\text {th }}$ International Conference on Applications of Statistics and Probability in Civil Engineering (ICASP).

Malioka, V. (2009). Condition Indicators for the Assessment of Local and Spatial Deterioration of Concrete Structures. (PhD Thesis), Swiss Federal Institute of Technology Zurich (ETH Zürich).

Schieß1, P. \& Mayer, T.F. (2007). Lebensdauer Managementsystem - Teilprojekt A2. DAfStb-Heft 572.
Stewart, M.G. \& Mullard, J.A. (2007). Spatial time-dependent reliability analysis of corrosion damage and the timing of first repair for RC structures. Engineering Structures 29 (7): 1457-64.

Straub, D. (2011). Reliability updating with equality information. Probabilistic Engineering Mechanics 26 (2): 254-8.

Tang, W.H. (1973). Probabilistic updating of flaw information (flaw prediction and control in welds). Journal of Testing and Evaluation 1 (6): 459-67.

Thöns, S. (2011). Monitoring Based Condition Assessment of Offshore Wind Turbine Support Structures. (PhD Thesis), Swiss Federal Institute of Technology Zurich (ETH Zürich). 